\title{
EdiTORIAL - EdUCAÇÃo
}

E MOVIMENTOS SOCIAIS:

UMA RELAÇÁO FORJADA NA PRÁTICA

Sabe-se que os movimentos sociais fazem parte da história da humanidade desde os tempos mais remotos. Eles podem ser localizados a partir de açôes de coletivos humanos na história, na luta pela sobrevivência ou defesa de seus interesses. $\mathrm{Na}$ atualidade, quando se fala de movimentos sociais, usualmente, faz-se referência a alguns tipos de ação coletiva advinda do mundo do trabalho ou da vida - para usarmos uma expressão de Habermas (1985). Os primeiros sempre ocuparam lugar clássico na literatura dos estudos sobre classe operária, na luta dos trabalhadores por melhores condições de salário ou de trabalho nas fábricas e oficinas, por meio de açóes coletivas de grupos ou órgãos de classes, a exemplo dos sindicatos. Os segundos se referem a melhores condiçóes de vida no cotidiano - quer materiais de moradia e serviços públicos, quer ambientais, ou lutas culturais contra discriminaçôes, injustiças sociais, desigualdades, busca de reconhecimento das diferenças, diversidade cultural etc.

Todos esses movimentos têm sempre caráter educativo. Esse é o primeiro ponto a ser destacado na apresentação deste dossiê sobre "Educação e Movimentos Sociais". Decorre deste ponto uma premissa fundamental que orienta a maioria dos textos aqui apresentados, qual seja: a educação não se resume à escola, à educação formal, escolar. Há aprendizagens e produção de saberes em outros espaços, aqui denominados de educação não formal. Portanto, trabalha-se com uma concepçáo ampla de educação.

O segundo ponto a ser destacado diz respeito aos espaços em que encontramos, na atualidade, a relação e o vínculo entre os dois termos principais do dossiê: educação e movimentos sociais. Essa relação existe na realidade, a 
partir das ações de movimentos e grupos sociais, mas na academia, nos fóruns de pesquisa e na produção teórico-metodológica, ela é relativamente recente, data das últimas décadas. A junção dos dois termos tem-se constituído em "novidade" em algumas áreas, como na própria Educação, causando reaçóes de júbilo pelo reconhecimento da relação, ou espanto e estranhamento, nas visóes ainda conservadoras de alguns. Essa relação foi sendo construída vagarosamente no Brasil e pode ser encontrada em fóruns de organizaçóes acadêmicas como a Anpocs (Associação Nacional de Pós-Graduação e Pesquisa em Ciências Sociais), a ANPEd (Associação Nacional de Pós-Graduação e Pesquisa em Educaçáo), a SBPC (Sociedade Brasileira para o Progresso da Ciência) e a SBS (Sociedade Brasileira de Sociologia). No exterior, a articulação dos movimentos com a educação é antiga e constitutiva de alguns grupos de pesquisa, como a ISA (International Sociological Association), a LASA (Latin American Studies Association) e a ALAS (Associación Latinoamericana de Sociologia). No cenário dos debates e da produção acadêmica brasileira, a relaçáo foi construída a partir dos anos 1970, quando foram criadas novas associaçóes ou ativadas entidades científicas já existentes, a exemplo da SBPC, da SBS e da CBE (Conferência Brasileira de Educação), as quais passaram a debater os problemas socioeconômicos e políticos e a destacar os grupos e movimentos sociais envolvidos. Essas entidades puseram em pauta, em seus GTs (Grupos de Trabalhos) de pesquisa, mesas e debates, o tema dos movimentos sociais, tendo sido apresentada sua relação com a educação, não de forma intencional, mas decorrente de um papel educativo desempenhado pelos movimentos junto a novos atores que entravam em cena, sujeitos de novas açóes coletivas, que extrapolavam o âmbito da fábrica, os locais de trabalho, envolvendo as periferias da cidade e suas necessidades. Já existe um acervo considerável de pesquisa sobre aquela época, composto de várias teses, dissertaçóes, livros e outros trabalhos acadêmicos sobre esses temas. Entretanto, deve-se considerar uma avaliação mais ampla, especialmente um balanço que não se limite ao eixo São Paulo, Rio e Minas Gerais, porque os movimentos 
ocorreram em todo Brasil. Faltam ainda mapeamentos que articulem essa produção com a de outros países latino-americanos, especialmente aqueles que também passaram por regimes militares. Em síntese, apesar do denso quadro de mobilizaçóes e movimentos sociais no Brasil a partir do final de I970, a produção teórica caminhou lentamente, e no campo da educação, a defasagem foi ainda maior.

O terceiro e último ponto a ser destacado neste editorial refere-se à relação educação-movimentos sociais na prática. Para não nos alongarmos demais na história, localizamos alguns movimentos sociais a partir da segunda metade do século XX, citando, por exemplo, as Ligas Camponesas, nos anos 1960, e a utilização do método Paulo Freire, além da importante relação entre a educação escolar do ensino superior e os movimentos sociais, nas mobilizaçôes ao redor de Maio de 1968. Nos primeiros anos da década de 1960, tivemos também uma série de movimentos sociais e populares preocupados com as questóes educacionais, entre os quais os de difusão da cultura popular, como os Centros Populares de Cultura (CPC), criados pela União Nacional dos Estudantes (UNE), as iniciativas de educação de adultos, como o Movimento de Educaçáo de Base (MEB), efetivado com o apoio da Confederaçáo dos Bispos do Brasil, que atuava no meio rural, utilizando-se do rádio, além da presença de vários movimentos que empregavam o "Método de Alfabetização de 40 horas", de Paulo Freire - que procurava, pela associaçáo entre o domínio cognitivo do letramento e a conscientização, inserir o educando no processo histórico -, tendo-se transformado no núcleo central do Plano Nacional de Alfabetização de Adultos, que se desenvolveu entre janeiro e abril de 1964.

Nos anos 1970, a relação é bem perceptível nas Comunidades de Base da Igreja (CEBs) com a educação não formal que, naquela época, formava politicamente os participantes, dando-lhes instrumentos para uma visão crítica de mundo. As CEBs eram a porta de entrada dos movimentos sociais urbanos na luta por creches, transportes, postos de saúde, moradia etc. Os professores, 
com a lei vigente, embora não pudessem participar de sindicatos, engajaramse em movimentos de resistência em suas associaçôes de classes. A universidade foi um grande palco de debates na época e, em conjunto com a SBPC, além de entidades como a OAB (Ordem dos Advogados do Brasil), associaçóes de jornalistas, Cúria Metropolitana e outros, acolheu os debates e participou dos atos de protesto contra o regime vigente.

Nos anos I980, as relaçóes entre educação e movimentos sociais se acentuam por meio de trabalhos de educação popular, da luta pelas Diretas Já - organização de propostas para a Constituinte - e da Constituiçáo propriamente dita. Os movimentos defendem uma nova agenda de demandas e uma nova cultura política também é construída, alterando as políticas públicas vigentes. Conselhos e Delegacias das mulheres, temas étnico-raciais, a mbientais etc. passam a fazer parte do cotidiano na transição do regime militar para a fase da redemocratização. Paulatinamente, constroem-se redes de movimentos sociais temáticos.

Os anos 1990 mudam a cena política. Com o fim do regime militar e ascensão de setores da oposição a cargos no poder, altera-se a composição política e o país começa a reconstruir sua institucionalidade. Novos atores entram em cena - como as entidades do Terceiro Setor. Muitos movimentos sociais se desmobilizam. Novas políticas públicas passam a nortear questóes da cidadania e participação, as políticas neoliberais ganham maior ênfase, os sindicatos se enfraquecem e a educação formal escolar, um dos alvos prediletos das reformas estatais, ganha uma nova Lei de Diretrizes e Bases (LDB).

A década em curso traz novíssimos atores, articulados a partir de políticas públicas ou parcerias entre a comunidade "organizada”, ONGs, fundaçóes etc. e setores do poder público. Projetos sociais passam a ter centralidade na forma de organização da população. Nestes novos tempos, as identidades são forjadas de cima para baixo. Fala-se em cidadania, mas, muitas vezes, os sujeitos das ações são tratados como usuários, consumidores. Nesse contexto, a Educação entra em cena de diferentes formas - como articuladora das redes 
de solidariedade/vulnerabilidade ou como elo entre escola e comunidade, na busca de soluçôes para problemas nas instituiçôes de ensino e fora delas, especialmente entre os jovens, em questóes como drogas, por exemplo. O leque de propostas e açóes é amplo. Há grupos sérios, competentes, com propostas articuladas, fundadas em projetos sociopolíticos e culturais emancipatórios.

Este editorial não tem o intuito de fazer um balanço crítico das relações que se estabelecem entre os movimentos sociais e as mais variadas áreas do conhecimento humanístico, e particularmente educacional, mas, sim, mostrar que elas existem há muito tempo; são fecundas e inspiradoras de uma série de reflexôes interpretativas dos rumos sociais e da formulação de propostas objetivando a intervenção na política institucionalizada ou não, como o conjunto de artigos aqui apresentados bem o demonstra.

\section{Dossiê temático: da educação e dos movimentos sociais, algumas possibilidades interpretativas}

Este dossiê traz para o debate as fecundas relaçôes que se estabelecem entre a educação e os movimentos sociais, possibilitando a articulação das reflexōes teóricas com o registro histórico e o de determinadas práticas que se desenvolvem na contemporaneidade, tendo consciência de suas imbricaçóes com a política, a economia e suas consequências na vida social.

Seus autores procuram desvelar o tempo presente e associá-lo à dimensáo histórica da qual os sujeitos emergem e em que atuam, seja nos cenários das lutas sociais, seja na produção de práticas povoadas de compromissos educativos.

Assim, não foi por acaso a escolha de Maria da Glória Gohn para fazer a abertura deste número, com o texto intitulado "Lutas e movimentos pela educaçáo no Brasil a partir de 1970 ". Nele, a autora resgata criticamente lutas e movimentos pela educação formal e não formal no Brasil pós-1970 e nos 
brinda com um mapeamento histórico desse período, focalizando ainda um dos sujeitos da educação - os profissionais da escola básica, atuando via sindical ou não.

Em "O movimento da educação do campo, as tensôes na luta por um direito social e os sinais da construção de políticas públicas", Maria Antônia de Souza procura problematizar a educação do campo e demonstrar os sinais da construção de políticas públicas que vem sendo viabilizada pela participação efetiva dos trabalhadores do campo.

Escrevendo sobre "O movimento social e a escola: da criaçáo passada à invenção necessária", José Adelson Cruz nos diz que seu objetivo é apreender os sentidos e significados das demandas pautadas pelos movimentos sociais para a escola e sua materialidade nas atuais políticas e legislação educacionais. Além disso, procura localizar e refletir sobre as idéias de democracia, qualidade e cidadania presentes na atuação de gestores, professores, técnicos administrativos, alunos e pais, como forma de compreender os valores e princípios estruturantes das práticas escolares, recuperando temas emergentes no debate atual.

Em "Movimientos sociales y educación en Argentina: una aproximación a los estudios recientes", Natalia Baraldo, da Universidade Nacional de Córdoba, parte do pressuposto de que, até pouquíssimo tempo, a dimensáo político-pedagógica dos movimentos populares emergentes, em decorrência da crise vivenciada pelos argentinos em 200I, foi um dos assuntos menos discutidos na produção teórica, tomando para si a tarefa de estudar essas ações.

\section{Seção Artigos}

A Seção Artigos é composta por dez textos, seis com forte aderência à temática do Dossiê, sendo os demais contribuiçôes espontâneas.

De pronto, Breno Bringel apresenta-nos "O futuro anterior: continuidades e rupturas nos movimentos estudantis do Brasil", artigo com o qual ob- 
serva que, ao longo de 2008, multiplicaram-se, em todo o mundo, as reflexóes sobre as lutas estudantis, segundo ele, por conta do quadragésimo aniversário do Maio de 68.

Mônica Rodrigues Costa discute "Os amálgamas das transformaçôes da educação popular" com o objetivo de situar a educaçáo popular como processo vivo que, particularmente na regiáo nordestina, nutre-se das lutas político-sociais. Para a autora, é preciso evidenciar seu contínuo movimento de transformação a partir das relaçóes que estabelece com as vivências formativas e novas requisiçóes apontadas pelos movimentos sociais nordestinos e pelo cenário atual de transformaçôes.

A discussão avança com Denise Mesquita de Melo Almeida, em seu artigo "Entre açóes coletivas e subjetividade: o caráter educativo dos movimentos sociais". Nele, busca-se compreender os movimentos sociais em sua dimensão educativa como elementos estruturantes da subjetividade dos sujeitos que os constituem.

Em seguida, temos o artigo "A universidade na educação do campo: elemento para a construção da história dos movimentos sociais", no qual Yolanda Zancanella aponta que uma série de conflitos que envolvem a posse de terras faz parte da história do Estado do Paraná, sendo também registradas lutas armadas, revoltas, desapropriação de terras e organização de movimentos sociais.

Em "A atuação do pedagogo no MST: revelaçôes de um estudo exploratório", Georgia Sobreira dos Santos Cêa, Camila Ferreira da Silva, Samara Santos Marques de Gusmão e Thayanne Araújo Silva, partindo da informação de que recentemente os cursos de graduação em Pedagogia foram definidos como uma licenciatura que deve prever a formaçáo desse profissional para atuação em espaços escolares e náo escolares, incluindo os movimentos sociais, dispóem-se a apresentar uma experiência curricular denominada "Projetos Integradores". Em linhas gerais, refletem sobre a importância do tratamento das relaçôes entre movimentos sociais e educação na formação de pedagogos. 
Dando continuidade ao conjunto de artigos que estão diretamente associados ao Dossiê, Ana Maria Alvarenga e António Teodoro analisam, em "A 'lenda' ou história da borboleta: os movimentos sociais e a educação - o caso do movimento dos trabalhadores rurais sem terra e a educação do campo", o papel do Movimento dos Trabalhadores Rurais Sem-Terra (MST) naquilo que entendem ser a reconstrução da educação popular no Brasil, na atual conjuntura de crise na educação formal. Para esses autores, o MST apresenta-se como um movimento social dinâmico, constantemente reinventado, alicerçando suas reivindicaçôes e açôes em prol de melhores condiçôes de vida e trabalho, numa permanente busca de afirmação identitária e de oposiçáo à globalização neoliberal.

No texto "Os profissionais da educaçáo e as relaçóes com a comunidade escolar: aprendizagens no processo de qualificação", Mara Regina Lemes Sordi e Menga Lüdke argumentam que o diálogo entre profissionais da educação e os múltiplos atores envolvidos nas redes públicas de ensino é reconhecidamente indispensável para a qualificação da escola e se desenvolve de modo mais concreto quando subsidiado por evidências produzidas em processos de avaliação institucional participativa.

Débora Cristina Jeffrey, em "A prática avaliativa e a ampliação do ensino fundamental para nove anos: desafios", apresenta um debate atual, relevante e necessário, apontando questốes que podem contribuir para que esse período de transição por que passa a educação seja de germinação de novas possibilidades para o Ensino Fundamental.

Logo em seguida, apresentamos o artigo "Alguns estudos sobre evasão e persistência de estudantes", de autoria de Kátia Siqueira de Freitas, no qual a autora reflete sobre alguns dos trabalhos que tratam da evasão e persistência de estudantes no sistema educacional presencial e a distância. É interessante notar que as pesquisas mencionadas foram realizadas em diferentes contextos sociais e em países como Inglaterra, Estados Unidos, Costa Rica, Venezuela, Uganda e Brasil. 
No fechamento deste número, temos o artigo "Relaçôes entre a prática da educação a distância e a estrutura organizacional das universidades", de Márcia Lopes Reis, no qual se considera a educação a distância como uma modalidade de ensino-aprendizagem cujo processo de inovação resulta em estruturaçáo e, simultaneamente, desestruturação de práticas institucionalizadas no próprio cotidiano da universidade.

Quiçá o conjunto de artigos aqui reunidos contribua para estimular as reflexóes e ampliar as discussóes que têm como intuito fortalecer a área da educação e trazer novas possibilidades interpretativas desta inquietante temática "Educação e movimentos sociais" e dos demais assuntos tratados neste número.

Carlos Bauer (editor)

Maria Dilnéia Espíndola Fernandes

Maria da Glória Marcondes Gohn 
